Article

\title{
When the Utility of Micro-Computed Tomography Collides with Insect Sample Preparation: An Entomologist User Guide to Solve Post-Processing Issues and Achieve Optimal 3D Models
}

\author{
Francesco Simone Mensa ${ }^{1}$ (D), Maurizio Muzzi ${ }^{1}$, Federica Spani ${ }^{1,2}{ }^{\mathbb{D}}$, Giuliana Tromba $^{3}$, Christian Dullin $^{4,5,6} \mathbb{D}^{\circ}$ \\ and Andrea Di Giulio 1,*(D) \\ 1 Department of Science, University of Roma Tre, 00146 Rome, Italy; \\ francescosimone.mensa@uniroma3.it (F.S.M.); maurizio.muzzi@uniroma3.it (M.M.); \\ f.spani@unicampus.it (F.S.) \\ 2 Diagnostic Imaging Unit, Departmental Faculty of Medicine and Surgery, Campus Bio-Medico University of \\ Rome, 00128 Rome, Italy \\ 3 Elettra-Sincrotrone Trieste, 34149 Basovizza, Italy; giuliana.tromba@elettra.eu \\ 4 Institute for Diagnostic and Interventional Radiology, University Medical Center Goettingen, \\ 37075 Goettingen, Germany; christian.dullin@med.uni-goettingen.de \\ 5 Max Plank Institute for Experimental Medicine, 37075 Goettingen, Germany \\ 6 Department for Diagnostic and Interventional Radiology, University Hospital Heidelberg, \\ 69120 Heidelberg, Germany \\ * Correspondence: andrea.digiulio@uniroma3.it
}

Citation: Mensa, F.S.; Muzzi, M.; Spani, F.; Tromba, G.; Dullin, C.; Di Giulio, A. When the Utility of Micro-Computed Tomography Collides with Insect Sample Preparation: An Entomologist User Guide to Solve Post-Processing Issues and Achieve Optimal 3D Models. Appl. Sci. 2022, 12, 769. https:// doi.org/10.3390/app12020769

Academic Editors: Alice Dal Fovo and Raffaella Fontana

Received: 9 November 2021

Accepted: 11 January 2022

Published: 13 January 2022

Publisher's Note: MDPI stays neutral with regard to jurisdictional claims in published maps and institutional affiliations.

Copyright: (C) 2022 by the authors Licensee MDPI, Basel, Switzerland. This article is an open access article distributed under the terms and conditions of the Creative Commons Attribution (CC BY) license (https:// creativecommons.org/licenses/by/ $4.0 /$ )

\begin{abstract}
Many techniques are used today to study insect morphology, including light and electron microscopy. Most of them require to specifically prepare the sample, precluding its use for further investigation. In contrast, micro-CT allows a sample to be studied in a non-destructive and rapid process, even without specific treatments that might hinder the use of rare and hard-to-find species in nature. We used synchrotron radiation (SR) micro-CT and conventional micro-CT to prepare 3D reconstructions of Diptera, Coleoptera, and Hymenoptera species that had been processed with 4 common preparation procedures: critical-point drying, sputter-coating, resin embedding, and air-drying. Our results showed that it is possible to further utilize insect samples prepared with the aforementioned preparation techniques for the creation of 3D models. Specimens dried at the critical point showed the best results, allowing us to faithfully reconstruct both their external surface and their internal structures, while sputter-coated insects were the most troublesome for the 3D reconstruction procedure. Air-dried specimens were suitable for external morphological analyses, while anatomical investigation of soft internal organs was not possible due to their shrinking and collapsing. The sample included in resin allowed us to reconstruct and appreciate the external cuticle and the internal parts. In this work, we demonstrate that insect samples destined to different analyses can be used for new micro-CT studies, further deepening the possibility of state-of-the-art morphological analyses.
\end{abstract}

Keywords: micro-CT; synchrotron radiation; 3D-models; morphology anatomy; entomology; coleoptera; hymenoptera; diptera

\section{Introduction}

Scientific research on insects is usually supported by a variety of techniques, which allow the gaining of knowledge on their morphology and anatomy [1]. Main morphological methods, such as photomicrography [2] and scanning electron microscopy (SEM) [3], aim at analyzing the cuticular structure and body surface of insects. In addition, anatomical studies often include one or more following approaches: histology [4-6], confocal scanner laser microscopy (CLSM) [7], light-sheet fluorescence microscopy (LSFM) [8], serial block-face 
scanning electron microscopy (SBSFM) [9], dual-beam scanning electron microscopy (FIBSEM) [10-13], nuclear magnetic resonance imaging (NMRI) [14,15], and micro-computed tomography (micro-CT) [16-18].

All these techniques have advantages and disadvantages and require specimen preparation before they can be performed. This, however, often makes it difficult to use a certain sample for other types of analysis, with different techniques and instruments. For example, a paraffin-embedded sample prepared for histological analysis may not be usable for subsequent electron microscopy. On the contrary, a sample embedded in the resin may be utilized for both electron microscopy and histology, if the resin sections are colored with, for instance, methylene blue or toluidine blue. Moreover, the scarcity of insects to be used may determine strong limitations regarding the technique to be chosen. In fact, it is not always possible to have many samples of a certain species and if destructive analyses were to be performed, for example by embedding, sputter-coating, or preparing them for histology, this would make it impossible to use the same samples for further studies using different techniques. Some specimens may come from old museum collections and be holotypes of a certain species, prohibiting the use of analyses schemes that would damage the specimens.

In order to study a certain rare sample or one that is difficult to collect in nature, one of the most versatile techniques remains scanning by micro-CT/synchrotron radiation (SR) micro-CT [19]. This is because micro-computed tomography is a non-destructive and very rapid (at least when compared to histology) three-dimensional imaging process, which results in virtual slices of even very small samples at high resolution [20], providing a high level of detail of both internal and external features. Another advantage of this technique is that specimens which had been previously prepared for TEM, SEM, or other kinds of investigations may still be able to be scanned. micro-CT is frequently used even when dealing with amber fossils [21-23], another type of specimen that is rare and hardly available in large numbers. If the number of samples available for a study is sufficient, and the species themselves are not extremely rare to find, the quality of the micro-CT scans can be improved by applying dedicated sample preparation steps, such as chemical or freeze-drying and/or heavy metal-based stainings. Usually, these tissue stainings lead to an improved image contrast, especially for soft-tissue components [24-26]. Some of the more common examples of stains are iodine, PTA, and silver staining. micro-CT is also useful for live imaging of whole invertebrates, for example by using carbon dioxide as an anesthetic and preventing animal movement during scanning [27].

In this work, specimens of the Diptera, Hymenoptera and Coleoptera insect orders were scanned via both micro-CT and SR-micro-CT, using four of the most frequently utilized types of sample preparation for morphological studies to improve the ability for the rendering of 3D models and evaluate the pros and cons of using samples for 3D reconstruction, that had not previously been prepared for micro-CT.

\section{Materials and Methods}

\subsection{Samples and Specimen Preparation}

A total of 84 specimens were scanned via both micro-CT and SR-micro-CT. Samples belonged to 3 insect orders: Coleoptera (73 paussine beetles), from the collections of Professor Andrea Di Giulio of the University of Roma Tre and Wendy Moore, Professor at the University of Tucson; Hymenoptera (4 ants) from collected specimens in Italy; and Diptera (4 mosquitoes and 3 hoveflies), collected from Italy and Great Britain (see Table 1 for a detailed list of specimens).

The samples were chosen from a variety of origins and preservation techniques. They were preserved and prepared as follows:

Air-dried samples: These samples were prepared by gluing them on cardboard with entomological glue, pinning them with entomological pins or kept in sachets, dry. 
Table 1. List of scanned specimens. CPD—Critical-Point Dried; CM-Cardboard Mounted; AD—Air Dried; SC—Sputter Coated; RE—Resin Embedded; PS—Pixel Size (in micrometers).

\begin{tabular}{|c|c|c|c|c|c|c|}
\hline Genera & $\begin{array}{l}\text { Species } \\
\text { Scanned }\end{array}$ & Scan Loc. & Scan Type & Sample Prep. & $\begin{array}{l}\text { No. of Axial Slices } \\
\text { (PS) }\end{array}$ & $\begin{array}{c}\text { Total Scanning } \\
\text { Time (h:mm) }\end{array}$ \\
\hline Aedes & 1 & Berlin & Micro-CT & $\mathrm{CPD}$ & $\begin{array}{l}2300 \\
(0.3) \\
\end{array}$ & 01:40 \\
\hline Anchomenus & 1 & Trieste & SR-Micro-CT & CPD & $\begin{array}{c}3400 \\
(0.95) \\
\end{array}$ & 0:06 \\
\hline Anopheles & 1 & Berlin & Micro-CT & CPD & $\begin{array}{l}2300 \\
(0.3)\end{array}$ & 01:40 \\
\hline Arthropterus & 1 & Berlin & Micro-CT & $\mathrm{CM}$ & $\begin{array}{l}2300 \\
(0.7)\end{array}$ & 01:48 \\
\hline Brachinus & 1 & Trieste & SR-Micro-CT & CPD & $\begin{array}{c}3400 \\
(0.95)\end{array}$ & 0:06 \\
\hline Carabidomemnus & 2 & Berlin & Micro-CT & $\mathrm{CM}$ & $\begin{array}{l}2300 \\
(0.6) \\
\end{array}$ & 01:48 \\
\hline Cerapterus & 1 & Trieste & SR-Micro-CT & $\mathrm{CM} / \mathrm{CPD}$ & $\begin{array}{c}6800 \\
(2.44)\end{array}$ & $0: 12$ \\
\hline Culex & 1 & Berlin & Micro-CT & CPD & $\begin{array}{l}2300 \\
(0.3) \\
\end{array}$ & 01:40 \\
\hline Culiseta & 1 & Berlin & Micro-CT & CPD & $\begin{array}{l}2300 \\
(0.3)\end{array}$ & 01:40 \\
\hline Dhanya & 1 & Berlin & Micro-CT & $\mathrm{CM}$ & $\begin{array}{l}2300 \\
(0.3)\end{array}$ & 01:30 \\
\hline Euplatyrhopalus & 1 & Berlin & Micro-CT & $\mathrm{CM}$ & $\begin{array}{l}2300 \\
(0.6) \\
\end{array}$ & 01:48 \\
\hline Eustra & 1 & Trieste & SR-Micro-CT & CPD & $\begin{array}{c}3400 \\
(0.95)\end{array}$ & $0: 06$ \\
\hline Filicerozaena & 1 & Trieste & SR-Micro-CT & CPD & $\begin{array}{c}5100 \\
(0.95)\end{array}$ & 0:09 \\
\hline Goniotropis & 1 & Trieste & SR-Micro-CT & $\mathrm{CPD}$ & $\begin{array}{l}5100 \\
(2.44)\end{array}$ & 0:09 \\
\hline Heteropaussus & 2 & Berlin & Micro-CT & $\mathrm{CM}$ & $\begin{array}{l}2300 \\
(0.6) \\
\end{array}$ & 01:48 \\
\hline Hylotorus & 1 & Berlin & Micro-CT & $\mathrm{CM}$ & $\begin{array}{l}2300 \\
(0.4) \\
\end{array}$ & 01:48 \\
\hline Messor & 2 & Berlin & Micro-CT & CPD & $\begin{array}{l}2300 \\
(0.3)\end{array}$ & 01:35 \\
\hline Metrius & 1 & Trieste & SR-Micro-CT & $\mathrm{CPD}$ & $\begin{array}{l}5100 \\
(2.44) \\
\end{array}$ & 0:09 \\
\hline Microdon & 2 & Trieste & SR-Micro-CT & $\mathrm{CPD}$ & $1700,5100(0.95)$ & $\begin{array}{l}0: 06 \\
0: 09\end{array}$ \\
\hline Microdon & 1 & Berlin & Micro-CT & $\mathrm{AD}$ & $\begin{array}{l}2300 \\
(0.3)\end{array}$ & $1: 36$ \\
\hline Mystropomus & 1 & Trieste & SR-Micro-CT & CPD & $\begin{array}{c}5100 \\
(2.44)\end{array}$ & 0:09 \\
\hline
\end{tabular}


Table 1. Cont.

\begin{tabular}{|c|c|c|c|c|c|c|}
\hline Genera & $\begin{array}{l}\text { Species } \\
\text { Scanned }\end{array}$ & Scan Loc. & Scan Type & Sample Prep. & $\begin{array}{l}\text { No. of Axial Slices } \\
\text { (PS) }\end{array}$ & $\begin{array}{c}\text { Total Scanning } \\
\text { Time (h:mm) }\end{array}$ \\
\hline Ozaena & 1 & Berlin & Micro-CT & $\mathrm{CM}$ & $\begin{array}{c}2300 \\
(1)\end{array}$ & 01:48 \\
\hline Pachyteles & 2 & Trieste & SR-Micro-CT & CPD & $\begin{array}{l}5100 \\
3400 \\
(0.95)\end{array}$ & $\begin{array}{l}0: 09 \\
0: 06\end{array}$ \\
\hline Paussomorphus & 1 & Trieste & SR-Micro-CT & $\mathrm{CM} / \mathrm{CPD}$ & $\begin{array}{l}3400 \\
(0.95)\end{array}$ & 0:06 \\
\hline Paussus & 10 & Trieste & SR-Micro-CT & $\mathrm{CPD} / \mathrm{RE}$ & $\begin{array}{c}8500,6400,1100 \\
(0.95)\end{array}$ & $\begin{array}{l}0: 15 \\
0: 12 \\
0: 03\end{array}$ \\
\hline Paussus & 37 & Berlin & Micro-CT & $\begin{array}{l}\mathrm{AD} / \mathrm{CM} / \\
\mathrm{CPD} / \mathrm{SC}\end{array}$ & $\begin{array}{c}1300 \\
2300 \\
(0.3 \text { to } 0.7)\end{array}$ & $\begin{array}{l}1: 30 \\
1: 48\end{array}$ \\
\hline Pentaplatarthus & 1 & Trieste & SR-Micro-CT & $\mathrm{CPD}$ & $\begin{array}{l}5100 \\
(0.95)\end{array}$ & 0:09 \\
\hline Pheidole & 2 & Trieste & SR-Micro-CT & CPD & $\begin{array}{c}2300,1650 \\
(0.95)\end{array}$ & $\begin{array}{c}0: 03 \\
01: 40\end{array}$ \\
\hline Pheropsophus & 1 & Trieste & SR-Micro-CT & $\mathrm{CPD}$ & $\begin{array}{l}3400 \\
(2.44) \\
\end{array}$ & 0:06 \\
\hline Physea & 1 & Trieste & SR-Micro-CT & $\mathrm{CM} / \mathrm{CPD}$ & $\begin{array}{l}6800 \\
(2.44)\end{array}$ & $0: 12$ \\
\hline Platyrhopalopsis & 1 & Berlin & Micro-CT & $\mathrm{CM}$ & $\begin{array}{l}2300 \\
(0.6) \\
\end{array}$ & 01:48 \\
\hline Platyrhopalus & 1 & Berlin & Micro-CT & $\mathrm{CM}$ & $\begin{array}{l}2300 \\
(0.4) \\
\end{array}$ & 01:48 \\
\hline Protopaussus & 1 & Berlin & Micro-CT & $\mathrm{CM}$ & $\begin{array}{l}2300 \\
(0.3)\end{array}$ & 01:48 \\
\hline
\end{tabular}

Critical-point dried samples: These samples were preserved via critical point drying and were prepared by fixing them in increasing percentages of ethanol, from $10 \%$ to $100 \%$, thus decreasing the concentration of water inside the sample. Then, the percentage of ethanol was replaced by using $\mathrm{CO}_{2}$ during a critical point drying procedure, in which the sample loses all internal liquids and gets replaced with gaseous carbon dioxide [28].

Resin embedded samples: The protocol for embedding samples in resin, like that for paraffin-embedding, starts with the fixation by immersion or perfusion, followed by dehydration, infiltration with liquid resin and finally polymerization, to get the resin solid.

Sputter-coated samples: For sputter-coated samples, the procedure is the same as the critical point dried ones. The sample then gets coated with a precious metal (usually gold, platinum or similar), to get better refraction of the atoms during the subsequent SEM analysis.

\subsection{Micro-CT Analyses}

In micro-CT devices, in contrast to clinical CTs, typically the X-ray source and detector are stationary and the sample is rotated. A multitude of angular projection images over a range typically of 180 to $360^{\circ}$ is acquired, allowing for a 3D reconstruction of the specimen. Micro-CT use micro- or nanofocus X-ray tubes and high-resolution detectors that allow spatial resolutions in the range of a few micrometers, however come at a cost of long scanning times, typically of several hours. 
Images were acquired at the Museum fur Naturkunde (Berlin, Germany) by using the micro-CT "Nanotom S" (GE Phoenix) equipped with a Tungsten target, able to achieve a resolution of $1 \mu \mathrm{m}$. The average energy was $20 \mathrm{keV}$, the acceleration voltage $50 \mathrm{kV}$, and the current $200 / 250 \mu \mathrm{A}$; every specimen was rotated of $360^{\circ}$ at steps of $0.25^{\circ}$ for a total of 1441 projections $(2304 \times 2304$ pixels $)$. Additionally, 3D data sets with a voxel size between $1 \mu \mathrm{m}$ and $0.3 \mu \mathrm{m}$ were reconstructed depending on the size of the specimen. In this case, the whole specimens were acquired in a single scan, and the data did not need to be reduced before further processing. See Table 2 for an overview of the scan settings.

Table 2. SR-micro-CT and micro-CT scan settings.

\begin{tabular}{ccc} 
& SR-Micro-CT & Micro-CT \\
\hline rotation & $180^{\circ}$ or $360^{\circ}$ & $360^{\circ}$ \\
\hline rotation steps & $0.2^{\circ}$ & $0.25^{\circ}$ \\
\hline avg. Acquisition time & $100 \mathrm{~ms}$ & $1 \mathrm{~s}$ \\
\hline avg. Energy & $22 \mathrm{keV}$ & $20 \mathrm{keV}$ \\
\hline sample/detector distance & $100 \mathrm{~mm}$ & $200 \mathrm{~mm}$ to $600 \mathrm{~mm}$ \\
\hline pixel size & $2.44 \mu \mathrm{m}$ to $0.95 \mu \mathrm{m}$ & $1 \mu \mathrm{m}$ to $0.3 \mu \mathrm{m}$ \\
\hline
\end{tabular}

\subsection{SR-Micro-CT Analyses}

Synchrotron can generate $X$-rays at very high photon flux densities, with high brightness, small-angle beam divergence, a high level of polarization and coherence, with low emissivity, and with a possibility of monochromatization. This high flux allows for reaching very short total acquisition times of a few minutes compared to classical micro-CT. The high level of coherence enables exploitation of the wave nature of the X-rays to, for instance, perform phase-contrast CT-a technique that has been proven to dramatically increase the contrast of soft tissue while at the same time reducing the needed X-ray dose [29].

Microtomography scans were performed at the "Elettra SYRMEP" synchrotron light source (Trieste, Italy) [30], using the white/pink beam micro-CT station in white beam configuration and, according to the dimension of the samples, projections were acquired over a total rotation of either $180^{\circ}$ or $360^{\circ}$ through steps of $0.2^{\circ}$ (total of $900-1800$ projections, respectively $2040 \times 2040-3870 \times 3870$ pixels) with an average acquisition time of $100 \mathrm{~ms}$ per projection. The average beam energy was $22 \mathrm{keV}$ and the sample to detector distance was set at $100 \mathrm{~mm}$. Due to the different dimensions of the samples (length ranging from $2 \mathrm{~mm}$ to $3 \mathrm{~cm}$ ), the specimens were studied at different resolution scales (with a pixel size from $2.44 \mu \mathrm{m}$ to $0.95 \mu \mathrm{m}$ ). To obtain broad morphological data on both the internal anatomy and external morphology of the insects, the field of view was limited to parts of the insect (i.e., head, thorax, and abdomen) leading to multiple scans for each sample. Tomographic slices were not binned or reduced, and were reconstructed using the conventional filtered back-projection algorithm with the Shepp-Logan filter, and using the Syrmep Tomo Project (STP) software [31]. See Table 2 for an overview of the scan settings.

\subsection{Mesh Creation Process}

The resulting virtual slice stacks were aligned using ImageJ 1.52p and Adobe Photoshop CC 2019 software. In ImageJ, the crop function was used to eliminate the unessential parts of the slices and reduce their final size. When necessary, the brightness/contrast function was used to increase the regions of interest in the resulting slices (Figure 1a). For the Elettra synchrotron specimens, Photoshop was used to reorient the different parts of the specimen's stacks of slices (for the head, thorax, and abdomen). This resulted in a single stack for the entire sample, ready to be imported into the 3D visualization software. Furthermore, 3D rendering was performed using Thermo Scientific Avizo 2019.1 (Figure 1b). The sequence of slices was loaded into the program, by specifying the $X, Y$, and $Z$ voxel size. Then, in the main panel window, the "isosurface rendering" module was attached to the 
stack, and in its properties, the threshold slider was used to better visualize the specimen in 3D, by virtually removing the noise in the sample. The "isosurface" module was used by applying the value from the "isosurface rendering" threshold, and this allowed to extract the surface of the 2D slices in a complete, external 3D model of the paussine by using the "extract surface" module and exporting it as a .ply mesh. To visualize the internal organs, segmentation was first necessary to then export the parts as separate meshes. For some specimens, it was necessary to remove the cardboard on which they were glued, and this has been possible by using the segmentation editor in Avizo (Figure 1c). The brush tool has been used for selecting the cardboard parts of the slices; then, after interpolating all the slices, it was possible to subtract said parts, resulting in a complete model without useless parts and was ready to be exported as a .ply mesh. The resulting meshes were later imported into 3D Systems Geomagic Design X 2019.0.2, which was used to further improve the 3D models. In particular, the "healing wizard" automatically heals various defects in the mesh (Figure 1d). For the more problematic samples (i.e., the ones from old museal collections), the "smooth" and "defeature" functions were used to remove any speck of dust that may have settled on its surface. "Enhance shape" was also used, when necessary, to improve the quality of the mesh by sharpening corners and smoothing flat or rounded areas.
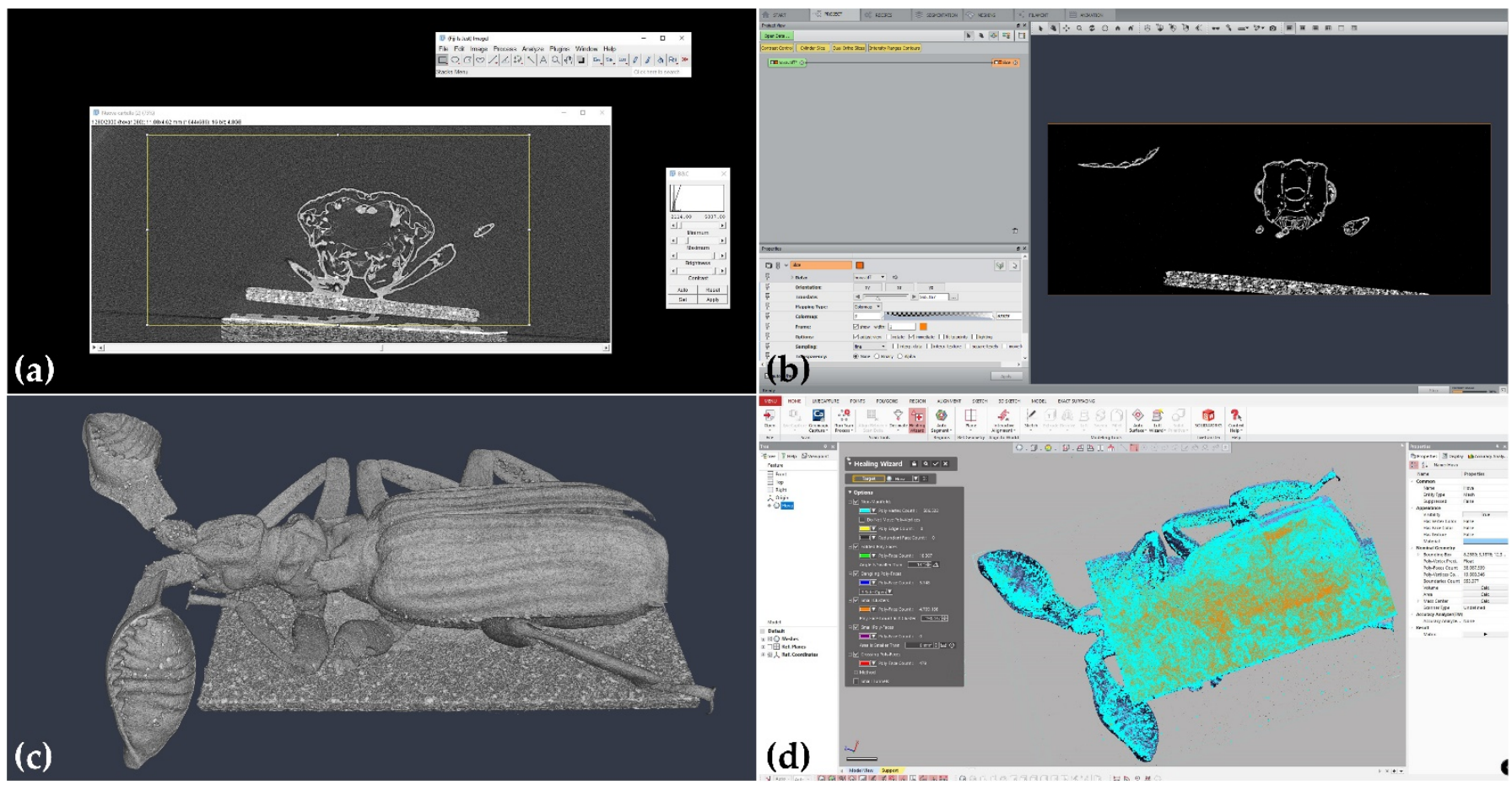

Figure 1. 3D model creation steps. (a) Example of a virtual slice sequence imported into ImageJ to enhance the contrast; (b) The stack is imported in Thermo Scientific Avizo to start the volume data rendering; (c) The resulting mesh, ready to be exported; (d) The 3D mesh is imported into Geomagic Design $X$ for removing artifacts and imperfections with the "Healing Wizard".

\section{Results}

3.1. Air-Dried Samples

\subsubsection{Coleoptera}

Coleoptera belonging to the following genera were reconstructed: Arthropterus, Carabidomemnus, Cerapterus, Dhanya, Euplatyrhopalus, Heteropaussus, Hylotorus, Ozaena, Paussomorphus, Paussus, Physea, Platyrhopalopsis, Platyrhopalus, Protopaussus.

For all these models, the external surface resulted intact and most of the details were visible (Figure 2a), although finer details, such as hairs, generally could not be retained during the 3D model creation process (Figure $2 \mathrm{~b}$ ). The thick and sturdy outer cuticle of 
these insects meant that the resulting gray level was distinguishable once the slices were imported into Avizo.
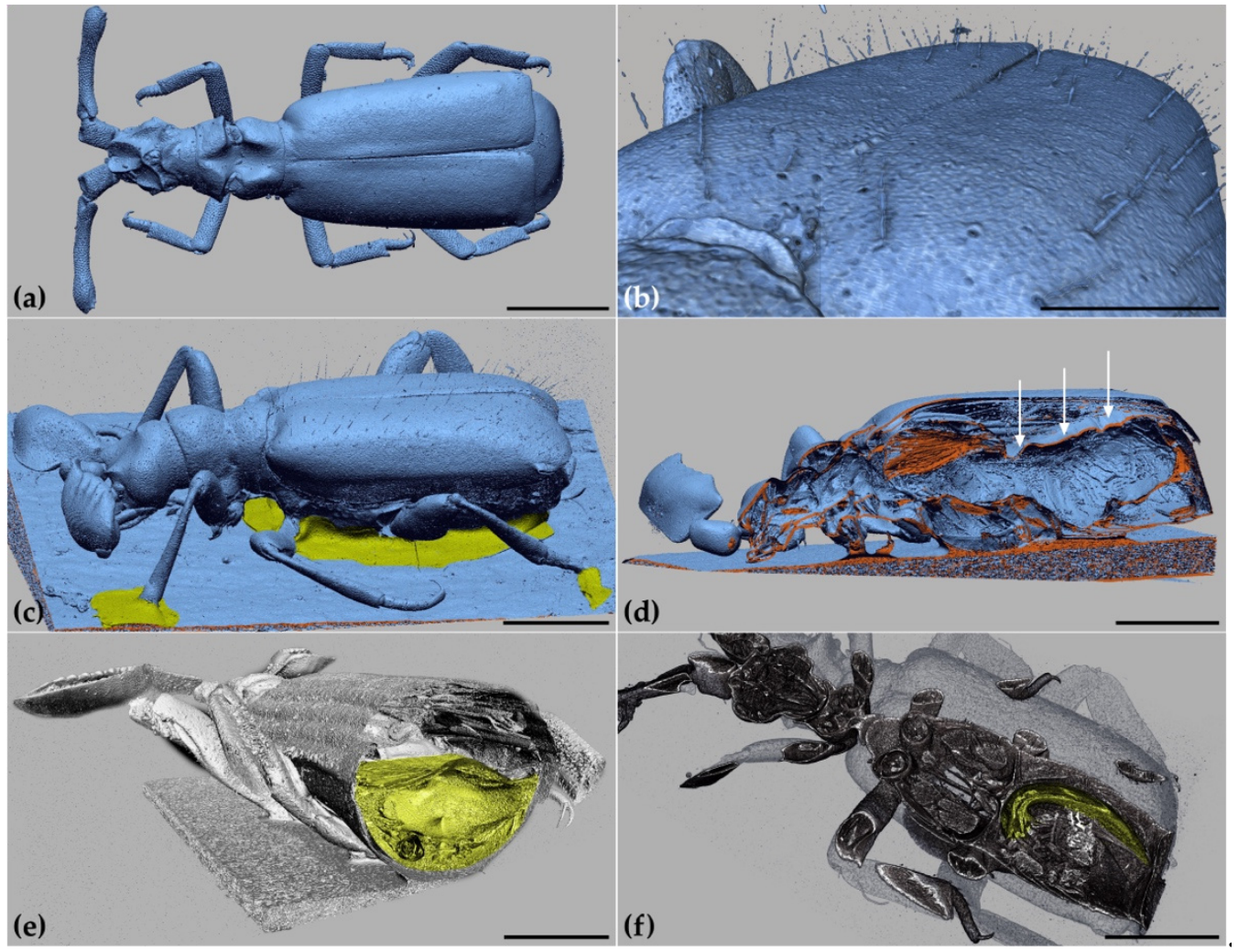

Figure 2. 3D models from air-dried Coleoptera. (a) External surface of a Paussus curtisi; (b) Detail of Paussus favieri elytra. Note how some fine details like hairs were lost during the 3D visualization procedure; (c) Paussus favieri glued to cardboard with glue (in yellow) covering parts of the legs, abdomen, and mouthparts (not visible); (d) Internal view of Paussus centurio, showing the collapsed abdomen as pointed by white arrows; (e) Virtual cross-section of Paussus howa showing artifacts due to the air-drying process, with shrunken internal organs (in yellow); (f) The 3D model of a male Paussus batillarius, with the preserved aedeagus (in yellow). Scalebars: (a) $-2 \mathrm{~mm}$; (b) $-0.5 \mathrm{~mm}$; (c) $-1 \mathrm{~mm}$; (d) $-2 \mathrm{~mm}$; (e) $-1 \mathrm{~mm}$; (f) $-0.5 \mathrm{~mm}$.

Samples that had been glued on cardboard (e.g., Paussus favieri) in some cases had great amounts of glue, especially at the level of the mouthparts and the lower part of the thorax/abdomen (Figure 2c). This made it necessary to meticulously remove the glue that covered some important parts of the body, such as mandibles, jaws, and tarsi, paying particular attention to not remove or incorrectly modify them. In cases where holes appeared because of the manual removal, it was necessary to use the Geomagic Design $X$ software function "Fill Holes", which fill missing holes with poly-faces based on the local mesh shape. The same was necessary in the case of the samples that had been pinned, to close the hole caused by the pin itself.

The antennal shapes of these beetles, belonging to the subfamily paussine, are completely visible and the 3D models can be freely manipulated-removing (if necessary) parts of the body to better visualize them.

For the beetles that were reconstructed from such dry preserved specimens, the abdomen was usually collapsed (Figure $2 \mathrm{~d}, \mathrm{e}$ ). This is also the case for beetles that were reconstructed from such preserved specimens. Below the elytra, the abdomen was almost always collapsed, and this determined that even a large part of the internal organs was no longer preserved, and thus, not allowing for a correct visualization in 3D or segmentation. 
Some better-preserved parts were instead possible to reconstruct, such as the aedeagus of some males-a very important diagnostic character for these beetles (Figure 2f).

\subsubsection{Diptera}

Diptera belonging to the following genera were reconstructed: Microdon.

Concerning Microdon, this genus consists of 3 larval stages of development. For this work, only the second stage (referred to as L2) was air-dried. The final 3D model presents an external surface without problems (Figure 3a), thanks also to the rather thick cuticle that characterizes this animal, used for its protection from possible attacks by ants. The support on which the sample was fixed during scanning had to be removed manually, as its gray value was equal to that of the actual sample. This required further work during the volume data analysis, but once done, it allowed for the model to be "clean" from any other external body and "noise-free".
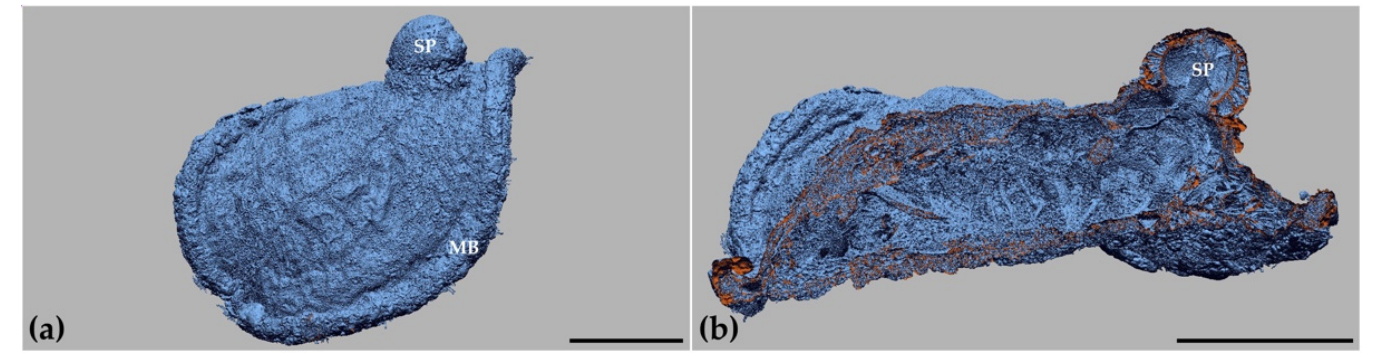

Figure 3. Air-dried Microdon, the second larval stage (L2). The external surface (a) did not present problems during the $3 \mathrm{D}$ visualization, while the insides (b) had an absorption peak too similar to the external environment, causing the impossibility of an easy and quick segmentation process. SP—spiracle; MB—marginal band. Scalebars: (a) $-1 \mathrm{~mm},(\mathbf{b})-1 \mathrm{~mm}$.

The interior, as far as L2 is concerned, presented more problems (Figure 3b). In fact, the absorption peaks of the various internal organs were almost identical to the surrounding environment, preventing the possibility of performing a quicker segmentation for other samples, using interpolation. In this case, it turned out to be necessary to carry out a manual procedure, trying to identify slice by slice the various internal organs of interest and segmenting them without any other software help (as it was not possible to exploit the Avizo mask function's brush selection tool, under the segmentation tab).

\subsection{Critical-Point Dried Samples}

\subsubsection{Coleoptera}

Coleoptera belonging to the following genera were reconstructed: Anchomenus, Brachinus, Cerapterus, Eustra, Filicerozaena, Goniotropis, Metrius, Mystropomus, Pachyteles, Paussomorphus, Paussus, Pentaplatarthus, Physea.

All 3D models prepared from this group of specimens had an excellent level of detail on the external surface (Figure 4a). The pipette tips and foam used during the scanning, to avoid motion artifacts, were difficult to remove, as in many cases they covered some parts of the insects, such as the mouthparts or the legs. However, using Avizo and Geomagic Design $X$ software, it was possible to remove this material completely from the rest of the beetle. For these models, scanned by synchrotron light, it was possible to preserve most of the finer parts of the body during the volume data analysis process, such as the hairs and bristles that cover parts of these beetles (Figure $4 \mathrm{~b}$ ), or the glandular openings, in the case of species of the genus Paussus. 

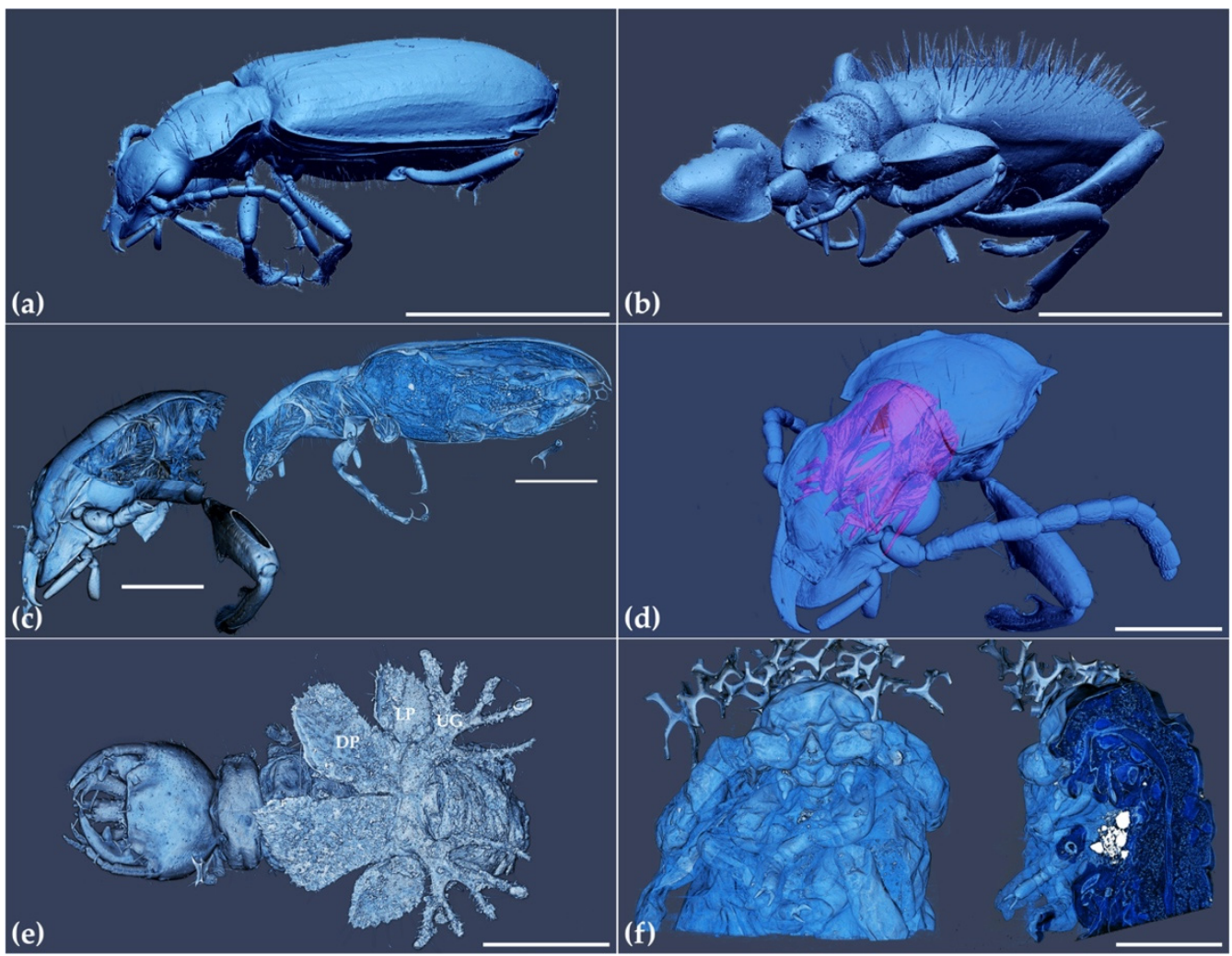

Figure 4. 3D models from critical-point dried Coleoptera. (a) External surface of a Pachyteles digiulioi; (b) Hairs and other finer details were able to be reconstructed from critical-point dried specimens; (c) Internal organs and structures were perfectly preserved and distinguishable; (d) The segmented cephalic musculature of Pachyteles digiulioi, was clearly visible from the rest of the head; (e) Immature stage of Goniotropis sp., with a focus on the terminal disc and its sensorial structures; (f) Pupa of Paussus otini, from a ventral view (left) and a virtual section with the internal organs visible (right). $\mathrm{DP}$ —dorsal plate; LP—lateral plate; UG—urogomphus. Scalebars: (a) $-0.4 \mathrm{~cm}$; (b) $-2 \mathrm{~mm}$; (c)—left $1 \mathrm{~mm}$, right $2 \mathrm{~mm}$; (d) $-1 \mathrm{~mm}$; (e)-2 $\mathrm{mm}$; (f) $-1 \mathrm{~mm}$.

An excellent state of preservation was also maintained by all the internal organs (Figure 4c). In fact, in almost all the specimens, it was possible to reconstruct perfectly all the musculature (e.g., the cephalic muscles, Figure 4d), as well as other organs (e.g., the digestive system, the nervous system, and the numerous glands found in the body of these animals). The mouthparts were also easily reconstructed, highlighting the joints of mandibles, maxillae, and palpi. The external and internal genital organs have also been perfectly preserved following the 3D volume creation process, being able to be segmented to extract them "virtually", if necessary.

Immature stages (Paussus otini, larva and pupa; Pachyteles digiulioi and Goniotropis kuntzeni, larvae) were reconstructed using synchrotron light radiation. The three larvae presented high quality in the final models and allowed us to appreciate the finer morphological details, for example, the sensorial structures of the terminal disc typical of the larval stages of these insects (Figure 4e). It was also possible to reconstruct the musculature and internal organs, and were easily identifiable in the final $3 \mathrm{D}$ rendering. This allows us to establish the spatial relationships between the various parts. The pupa of Paussus otini, in its internal regions, presented large amounts of fat bodies; its developing organs were clearly visible, and the external cuticle featured all the parts easily discernible (Figure 4f).

\subsubsection{Diptera}

Diptera belonging to the following genera were reconstructed: Aedes, Anopheles, Culex, Culiseta, Microdon. 
Because mosquitoes have a much thinner outer cuticle than beetles, the individuals scanned and reconstructed presented some problems regarding the level of gray on the body compared to that of the surrounding environment. Specifically, the abdomen could not be completely preserved following the 3D image analysis procedures with Avizo (Figure 5a), while the head and the thorax presented a good level of detail, even after cleaning the noise that surrounded the models freshly imported into the software. The ommatidia are easily discernible (Figure 5b), as well as the antennae and legs. The considerable hairiness, however, was not possible to maintain in the final model.

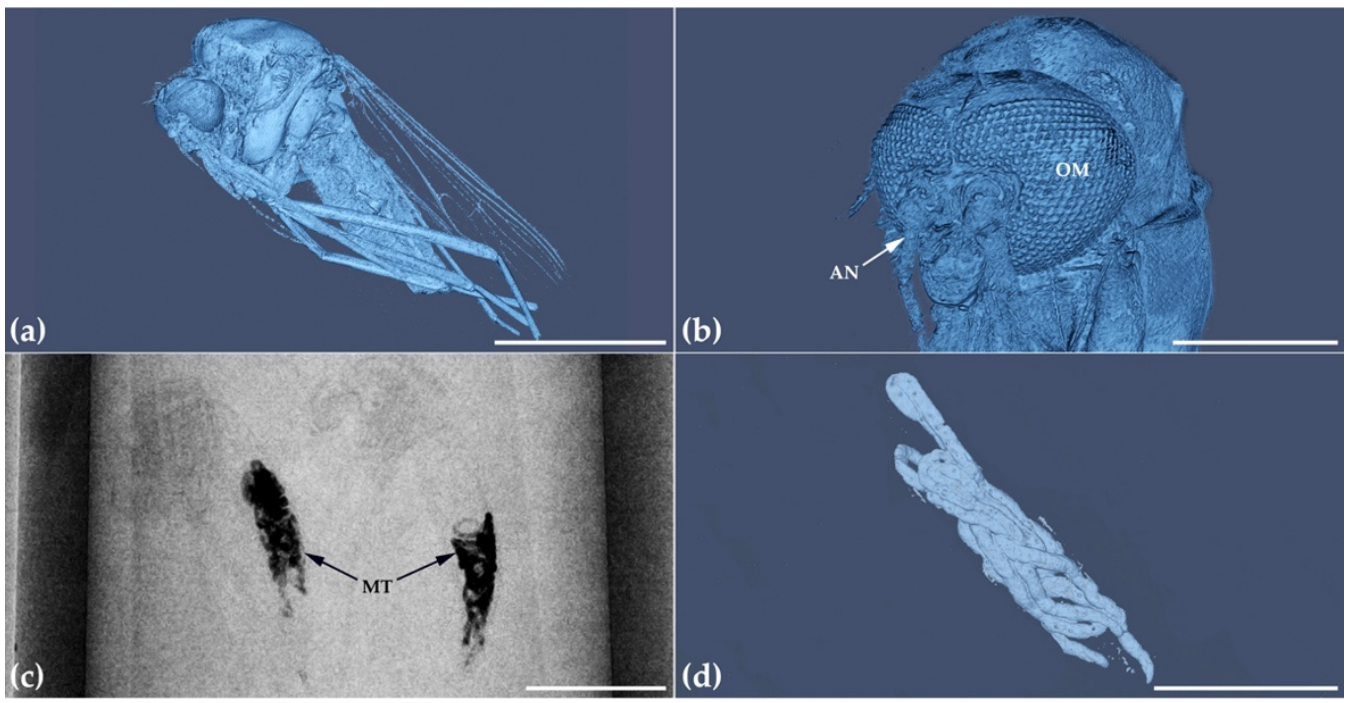

Figure 5. Critical-point dried mosquitoes. (a) External surface of a 3D Culiseta, with the abdomen not completely reconstructed due to a cuticle too thin for the differentiation of the gray level from the external environment; (b) Focus on the finer details, like the ommatidia of the compound eyes and part of the antennae; (c) The contrasted Malpighian tubules visible in the virtual slices; (d) The Malpighian tubules once they had been 3D reconstructed. AN-antenna; OM-ommatidia; MT—Malpighian tubules. Scalebars: (a) $-2 \mathrm{~mm}$; (b) $-0.5 \mathrm{~mm}$; (c) $-2 \mathrm{~mm}$; (d) $-2 \mathrm{~mm}$.

Regarding the internal organs, the Malpighian tubules showed a great contrast as opposed to other organs/apparatus, and this allowed us to visualize them perfectly in all scanned genera (Figure 5c,d).

The first and third larval stages (abbreviated as L1 and L3) of Microdon were reconstructed starting from critical-point dried samples. As with the beetles just described, L1 and L3 were scanned using synchrotron light. This resulted in the final 3D models with an excellent level of detail both internally and externally.

Regarding the external morphology, despite the extremely small size of L1, all major distinguishing features are visualized in the model. The same is true for the third-stage larva, L3. Indeed, the spiracle, the marginal band, and the dorsal reticulation were all observable (Figure 6a-c).

The internal areas of the two larvae presented peaks of absorption that were very poorly differentiated from those of the outside, causing some problems in distinguishing some internal organs (Figure $6 \mathrm{~d}$ ). Despite this, it was still possible to segment all the main organs and apparatus of both larval stages (Figure 6b). 


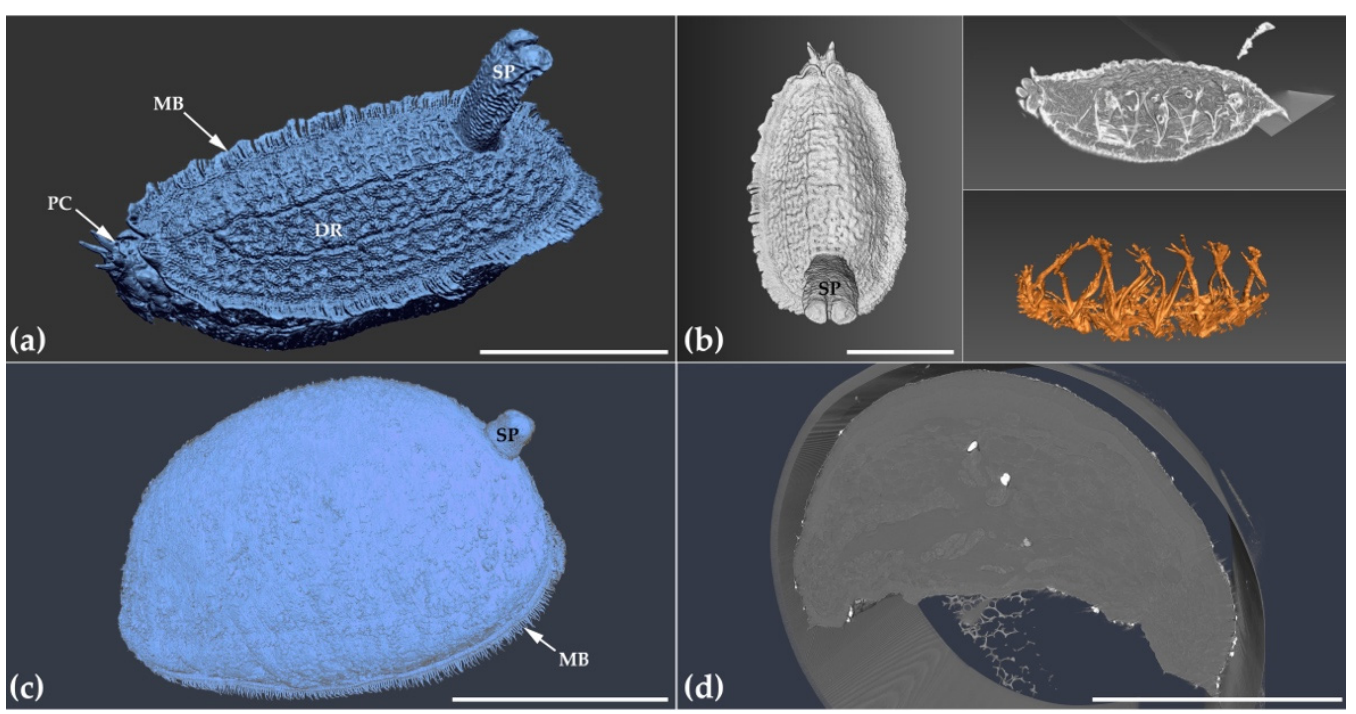

Figure 6. Critical-point dried Microdon larvae. (a) External 3D view of the first larval stage (L1) of Microdon mutabilis, with the spiracle, marginal band, and dorsal reticulation visible; (b) Dorsal view of L1 (left), virtual section (right, above) of the internal structures visible and segmented musculature (right, below) isolated from the rest of the body; (c) External 3D view of the third larval stage (L3) of Microdon mutabilis, with the spiracle and marginal band reduced from L1, but still easily discernible; (d) Virtual section of L3, with a similar peak of absorption that caused to render the internal organs and structures not clearly visible. SP — spiracle; $\mathrm{MB}$ - marginal band; PC—pseudocephalon; DR—dorsal reticulation. Scalebars: (a) $-0.5 \mathrm{~mm}$; (b) $-0.5 \mathrm{~mm}$; (c) $-0.5 \mathrm{~cm}$; (d) $-0.5 \mathrm{~cm}$.

\subsubsection{Hymenoptera}

Hymenoptera belonging to the following genera were reconstructed: Messor, Pheidole.

For these genera, both minor and major were scanned. In the case of Messor, the large size of these insects made the final model rich in details, such as the frontal ridges that characterize this genus and allow (together with other characters) its identification. The level of detail on the external surface was very high (Figure 7a).

As for the interior, once all the external cuticle was removed virtually, the musculature remained perfectly intact along the entire length of the animal's body (Figure 7b). The digestive system also appears to be well preserved and could be easily segmented. Part of the internal organs of the abdominal area could be identified in the final 3D model. As in the case of mosquitoes, the Malpighian tubules were well distinguishable thanks to a lighter shade of gray than the other surrounding parts.

The models belonging to the genus Pheidole ( $P$. Pallidula) presented a similar situation to what has been described so far. Despite the smaller size compared to Messor, the external surface showed a good resolution and the main features useful for the identification of this genus were perfectly visible, such as the clypeus and the frontal triangle (Figure 7c). In this case, especially for the major caste, the musculature was well visible and recognizable (Figure 7d) as for Messor, as well as the main internal organs. However, the external part of the abdomen could not be preserved during the cleaning procedure with Avizo, being too thin and too similar in gray values to the background noise. This resulted in most of the outer cuticle of this body part being impossible to visualize. 


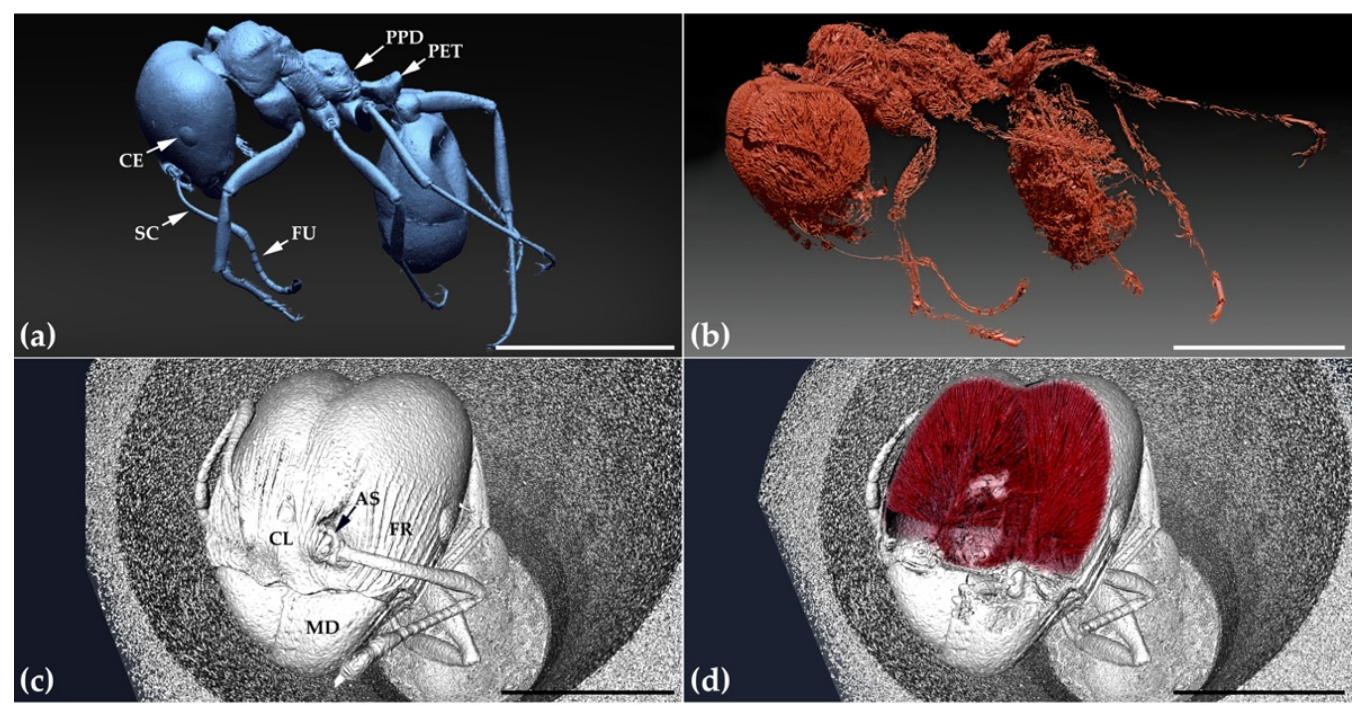

Figure 7. Critical-point dried Hymenoptera. (a) External 3D view of Messor sp. with the main characters for the identification visible; (b) Internal musculature of Messor sp., after virtually removing the external cuticle; (c) 3D head of Pheidole pallidula, with the frontal triangle, clypeus and ridges all visible and preserved; (d) Virtual section with the cephalic musculature, colored in red. CE-compound eye; SC—scape; FU—funicle; PET—petiole; PPD—propodeum; FR—frontal ridges; AS—antennal socket; MD—mandible; CL—clypeus. Scalebars: (a) $-0.5 \mathrm{~cm}$; (b) $-0.5 \mathrm{~cm}$; (c) $-1 \mathrm{~mm}$; (d) $-1 \mathrm{~mm}$.

\subsection{Resin Embedded Samples \\ Coleoptera}

Half of the transversally cut abdomen of a beetle of the genus Paussus (P. turcicus) has been reconstructed (Figure 8).

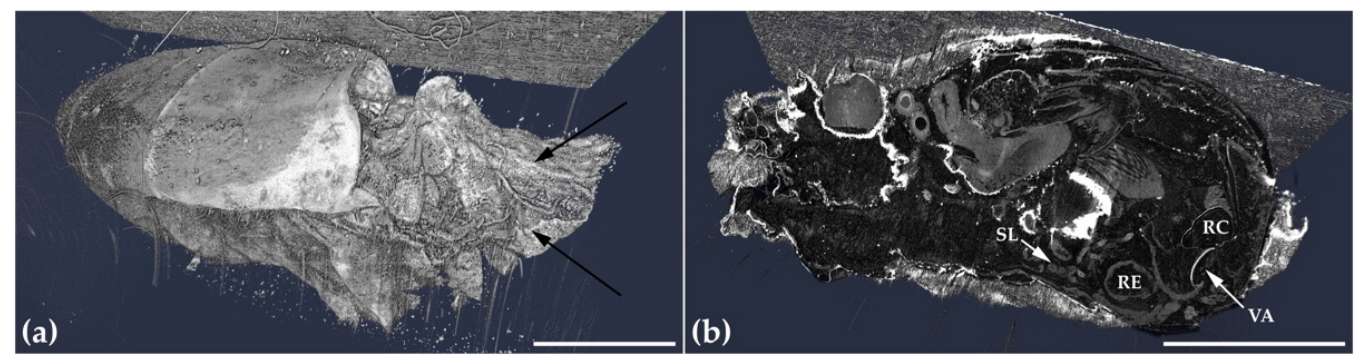

Figure 8. Resin embedded Coleoptera. (a) External 3D surface of the abdomen of Paussus turcicus. The arrows indicate the anterior part that got deformed during the cut; (b) internal rendering, with most of the internal structures exposed and visible, such as the pygidial explosive glands. SL-secretory lobe; RE—reservoir; VA—valve; RC—reaction chamber. Scalebars: (a) - $1 \mathrm{~mm}$; (b) -1 mm.

The process for TEM preparation of the sample has made the external surface particularly deformed, especially in its most anterior part, near the cuts (Figure 8a). On the contrary, the inner parts of this specimen are perfectly visible and with a well evident contrast (Figure $8 b$ ), while only very few parts present a peak of absorption too similar to the outside, thus was going to be almost completely lost during the setting of the threshold values of the rendered volume. To be more specific, the reservoir and the reaction chamber, typical of beetles belonging to this group, are visible in sections and allow us to perfectly appreciate these structures. The musculature presents a different absorption peak than the rest, making the various muscle groups clearly recognizable. The only problem was that in a few areas of the internal segment, some air bubbles did not allow the resin to infiltrate completely, thus creating a few artifacts. 


\subsection{Sputter Coated Samples \\ Coleoptera}

Antennae of species of the genus Paussus were reconstructed.

Once imported into the Avizo software, these structures presented background noise (Figure 9a), due to artifacts caused by the metal, which coated the antennal surface of these samples. This determined that by attempting to remove the noise, by going to change the volume threshold level, the antenna itself was also lost. Therefore, it was necessary to export the model into Geomagic Design X, to attempt to remove the noise manually, using the "Lasso Selection Mode". The result was better than that obtained with Avizo, but sometimes it was not possible to completely remove the noise surrounding the antennae without losing too much detail. In a few cases, otherwise, all the noise was removed while preserving the antennal surface (Figure $9 \mathrm{~b}$ ).

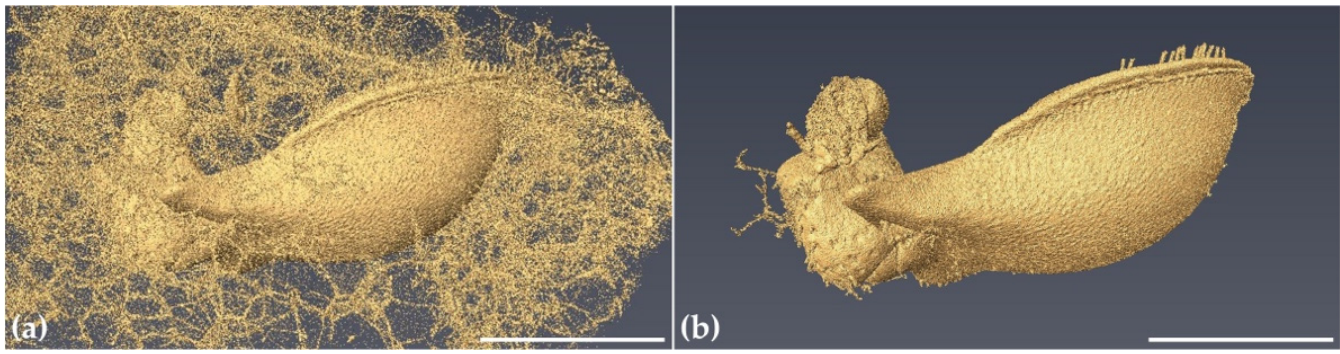

Figure 9. Sputter coated Coleoptera. (a) 3D render of Paussus antenna. Notice the surrounding noise, probably due to the artifacts caused by the gold-coating; (b) The same antenna, after being manually and semi-automatically cleaned from the external noise. Scalebars: (a) $-1 \mathrm{~mm}$; (b) $-1 \mathrm{~mm}$.

\section{Discussion}

Here, we presented our results using micro-CT and synchrotron micro-CT on 84 samples that belonged to 3 orders of insects: Coleoptera, Diptera and Hymenoptera. The samples had been stored and treated in different ways: air-dried, critical point dried, metallized and resin embedded. This allowed us to evaluate what could be the advantages and disadvantages of reconstructing models in $3 \mathrm{D}$ by using samples not specifically stained for micro-CT analyses [25], determining if it was possible to utilize specimens that had previously been used for other purposes (e.g., electron microscopy) with regard to 3D reconstruction.

Out of 84 total specimens, procedures for 3D image analysis and visualization could be performed on almost all of them. This is very important, as many samples used were coming from collections where they were the only specimens, preserved for many years without any treatment. Moreover, in the case of species belonging to the genus Paussus, the extreme rarity of these insects meant that no other specimens were available and that it was not possible to perform destructive procedures, such as dissections [32]. The latter, in fact, irreparably damage the specimen, which is not always possible in the case of holotypes or extremely rare species and is difficult to obtain in the field or from museums and other private collections $[18,33,34]$.

Thanks to 3D scanning and reconstruction techniques, today it is possible to study in detail many animal species without damaging their morphology $[19,27,35]$. In addition, scans by micro-CT do not appear to damage DNA or hinder further molecular analysis, although additional studies would need to be conducted as museum specimens vary widely in preservation methods and organism types [36].

In our case, the samples that allowed to obtain the best results were those that had been first fixed in absolute alcohol and then prepared by critical point drying. This, in fact, allowed for the almost perfect preservation of internal organs and musculature, also making the $3 \mathrm{D}$ volume creation procedure less troublesome. The gray value of these specimens was often well differentiated from the background, and this allowed to easily segment all parts that were of interest, such as the cephalic musculature. In the case of ants from the 
genus Messor, for example, it was sufficient to remove (virtually) the outer cuticle to get an overview of all the body musculature without having to perform other operations.

In the Coleoptera, a very important taxonomic character is the aedeagus. With the samples preserved by critical point drying, it was possible to segment and isolate this important organ without having to extract it manually (thus ruining the sample). However, even with air-dried samples, it was possible to extrapolate this type of information.

Insects coming from museum collections, prepared by gluing them on cards, presented a few more problems than described so far. In some cases, the amount of glue covering some parts of the animals (such as the mouthparts, the thorax, the legs, and part of the abdomen) proved difficult to remove digitally, without also removing some parts of the animal itself. In fact, the glue had a gray value like that of the external cuticle of the beetle, and this, therefore, forced a meticulous manual removal of the glue. The tag, on the other hand, proved to be easier to remove without having to resort to complex workflows both in Avizo and Geomagic software. Obviously in this type of specimen, unlike those described above, the internal organs and apparatus were collapsed and therefore could only be partially used for further analyses. Studies concerning the external surface are instead perfectly feasible, thus allowing to make the most of even old samples of museum collections.

Sputter-coated samples, previously used for electron microscopy, can hardly be used for works that require scanning by micro-CT and subsequent $3 \mathrm{D}$ visualization. In fact, the high absorbing quality of the gold layer that covers this type of sample has led to an excessive production of artifacts, which were extremely difficult to remove without affecting the surface of the insect itself. It would therefore be better to scan first and only later proceed with metallization.

Finally, in this work, there was also a portion of the abdomen of Paussus turcicus embedded in resin, for histological studies. In this case, as could be expected, the organs and internal tissues were well preserved and therefore usable for further analysis, following segmentation. However, since the specimen was only partially thus prepared (half of the abdomen), studies on external morphology are not possible.

\section{Conclusions}

Scanning techniques using micro-CT have now become increasingly common over the past 20 years, starting with primarily medical applications [36], and then extending into paleontology [34], the geosciences [37], and finally into entomology [26,38,39].

This has allowed samples from different sources to be used and further exploited, from a morphological/functional/evolutionary perspective [40,41].

With this work, we wanted to demonstrate the power of this technique, using samples of very rare insects and difficult to find (in nature or museums), prepared in different ways. We can resume our findings in the following points:

- $3 \mathrm{D}$ models will have the best details, especially for the interior organs when the samples are scanned with an SR-micro-CT, thanks to the higher resolution it can achieve, despite its higher pixel size value.

- When possible, it would be best to specifically prepare the samples for micro-CT (for example, with the staining methods reported in [25]).

- If the interest is mainly on the external surface of a specimen, even an old museum sample can be used (after the removal of dust on its cuticle).

- When is important to visualize and segment internal organs and structures, criticalpoint dried specimens produce the best results.

- The removal of the glue and cardboard in museum specimens, if possible, will yield better results in the final 3D model, and eliminate a lot of work to digitally remove those parts in the mesh.

- Finally, samples specifically prepared for Electron Microscopy (as in sputter-coated) will present a lot of artifacts in the final model, rendering them not easily usable. 
Our resulting 3D models can and will be used in the future for new interesting morphological analyses, and will guide additional histological and electron microscopy studies.

Author Contributions: Conceptualization, F.S.M., M.M., F.S. and A.D.G.; methodology, F.S.M., G.T., C.D., M.M. and A.D.G.; software, F.S.M., M.M., F.S., G.T. and C.D.; investigation, F.S.M., M.M. and A.D.G.; resources, A.D.G.; data curation, F.S.M., M.M. and A.D.G.; writing - original draft preparation, F.S.M.; writing - review and editing, F.S.M., M.M., F.S., G.T., C.D. and A.D.G.; visualization, F.S.M. and M.M.; supervision, F.S.M., M.M., F.S. and A.D.G.; project administration, A.D.G.; funding acquisition, M.M., G.T. and A.D.G. All authors have read and agreed to the published version of the manuscript.

Funding: This research was founded by the SYNTHESYS project (Synthesis of systematic resources, the European Union-funded Integrated Activity Grant), grant number DE-TAF-5591; ELETTRA SYRMEP (SYncrhotron Radiation for MEdical Physics) beamline, proposal number 20160088; DIPARTIMENTO DI ECCELLENZA (Grant of Excellence Departments, MIUR Italy, L.232/2016-Art. 1, commi 314-337) awarded to the Dept. of Science, University of Roma Tre, Rome, Italy 2018/2022.

Institutional Review Board Statement: Not applicable.

Informed Consent Statement: Not applicable.

Data Availability Statement: Data available on request.

Acknowledgments: We would like to thank Wendy Moore for providing us with some paussine samples used for this work; and Giulia Scarparo, for sampling Microdon specimens that have later been scanned for this study. We are also particularly grateful to Hannelore Hoch, Kristin Malhow, and Roland Mühlethaler for the help given during the acquisition of the data at the Museum für Naturkunde. Finally, we are deeply in debt with our friend, Hu Mongus, for his invaluable tips during the various steps for the creation of this manuscript.

Conflicts of Interest: The authors declare no conflict of interest.

\section{References}

1. Wipfler, B.; Pohl, H.; Yavorskaya, M.I.; Beutel, R.G. A Review of Methods for Analysing Insect Structures-The Role of Morphology in the Age of Phylogenomics. Curr. Opin. Insect Sci. 2016, 18, 60-68. [CrossRef] [PubMed]

2. Leubner, F.; Hörnschemeyer, T.; Bradler, S. The Thorax of the Cave Cricket Troglophilus Neglectus: Anatomical Adaptations in an Ancient Wingless Insect Lineage (Orthoptera: Rhaphidophoridae). BMC Evol. Biol. 2016, 16, 39. [CrossRef]

3. Cornford, M.E.; Rowley, W.A.; Klun, J.A. Scanning Electron Microscopy of Antennal Sensilla of the European Corn Borer, Ostrinia Nubilalis1. Ann. Entomol. Soc. Am. 1973, 66, 1079-1088. [CrossRef]

4. Glauert, A.M.; Glauert, R.H. Araldite as an Embedding Medium for Electron Microscopy. J. Biophys. Biochem. Cytol. 1958, 4, 191-194. [CrossRef]

5. Pernstich, A.; Krenn, H.W.; Pass, G. Preparation of Serial Sections of Arthropods Using 2,2-Dimethoxypropane Dehydration and Epoxy Resin Embedding under Vacuum. Biotech. Histochem. 2003, 78, 5-9. [CrossRef] [PubMed]

6. Gefen, S.; Tretiak, O.; Nissanov, J. Elastic 3-D Alignment of Rat Brain Histological Images. IEEE Trans. Med. Imaging 2003, 22, 1480-1489. [CrossRef]

7. Smolla, M.; Ruchty, M.; Nagel, M.; Kleineidam, C.J. Clearing Pigmented Insect Cuticle to Investigate Small Insects' Organs in Situ Using Confocal Laser-Scanning Microscopy (CLSM). Arthropod Struct. Dev. 2014, 43, 175-181. [CrossRef]

8. Strobl, F. Long-Term Fluorescence Live Imaging of Tribolium Castaneum Embryos: Principles, Resources, Scientific Challenges and the Comparative Approach. Curr. Opin. Insect Sci. 2016, 18, 17-26. [CrossRef]

9. Knauthe, P. Serial Block-Face Scanning Electron Microscopy Sheds New Light on the Head Anatomy of an Extremely Miniaturized Insect Larva (Strepsiptera). Arthropod Syst. Phylogeny 2016, 74, 107-126.

10. Stokes, D.J.; Morrissey, F.; Lich, B.H. A New Approach to Studying Biological and Soft Materials Using Focused Ion Beam Scanning Electron Microscopy (FIB SEM). J. Phys. Conf. Ser. 2006, 26, 50-53. [CrossRef]

11. Di Giulio, A.; Maurizi, E.; Rossi Stacconi, M.V.; Romani, R. Functional Structure of Antennal Sensilla in the Myrmecophilous Beetle Paussus Favieri (Coleoptera, Carabidae, Paussini). Micron 2012, 43, 705-719. [CrossRef] [PubMed]

12. Di Giulio, A.; Fattorini, S.; Moore, W.; Robertson, J.; Maurizi, E. Form, Function and Evolutionary Significance of Stridulatory Organs in Ant Nest Beetles (Coleoptera: Carabidae: Paussini). Eur. J. Entomol. 2014, 111, 692-702. [CrossRef]

13. Muzzi, M.; Di Giulio, A.; Mancini, E.; Fratini, E.; Cervelli, M.; Gasperi, T.; Mariottini, P.; Persichini, T.; Bologna, M.A. The Male Reproductive Accessory Glands of the Blister Beetle Meloe Proscarabaeus Linnaeus, 1758 (Coleoptera: Meloidae): Anatomy and Ultrastructure of the Cantharidin-Storing Organs. Arthropod Struct. Dev. 2020, 59, 100980. [CrossRef] 
14. Hallock, K.J. Magnetic Resonance Microscopy of Flows and Compressions of the Circulatory, Respiratory, and Digestive Systems in Pupae of the Tobacco Hornworm, Manduca sexta. J. Insect Sci. 2008, 8, 10. [CrossRef] [PubMed]

15. Ziegler, A.; Kunth, M.; Mueller, S.; Bock, C.; Pohmann, R.; Schröder, L.; Faber, C.; Giribet, G. Application of Magnetic Resonance Imaging in Zoology. Zoomorphology 2011, 130, 227-254. [CrossRef]

16. Hörnschemeyer, T.; Beutel, R.G.; Pasop, F. Head Structures of Priacma serrata Leconte (Coleptera, Archostemata) Inferred from X-ray Tomography: Head Structures of Priacma serrata. J. Morphol. 2002, 252, 298-314. [CrossRef] [PubMed]

17. Betz, O.; Wegst, U.; Weide, D.; Heethoff, M.; Helfen, L.; Lee, W.-K.; Cloetens, P. Imaging Applications of Synchrotron X-ray Phase-Contrast Microtomography in Biological Morphology and Biomaterials Science. I. General Aspects of the Technique and Its Advantages in the Analysis of Millimetre-Sized Arthropod Structure. J. Microsc. 2007, 227, 51-71. [CrossRef]

18. Spani, F.; Morigi, M.P.; Bettuzzi, M.; Scalici, M.; Carosi, M. A 3D Journey on Virtual Surfaces and Inner Structure of Ossa Genitalia in Primates by Means of a Non-Invasive Imaging Tool. PLoS ONE 2020, 15, e0228131. [CrossRef] [PubMed]

19. Tafforeau, P.; Boistel, R.; Boller, E.; Bravin, A.; Brunet, M.; Chaimanee, Y.; Cloetens, P.; Feist, M.; Hoszowska, J.; Jaeger, J.-J.; et al Applications of X-ray Synchrotron Microtomography for Non-Destructive 3D Studies of Paleontological Specimens. Appl. Phys. A 2006, 83, 195-202. [CrossRef]

20. Orhan, K. (Ed.) Micro-Computed Tomography (Micro-CT) in Medicine and Engineering; Springer International Publishing: Cham, Switzerland, 2020; ISBN 978-3-030-16640-3.

21. Pohl, H.; Wipfler, B.; Grimaldi, D.; Beckmann, F.; Beutel, R.G. Reconstructing the Anatomy of the 42-Million-Year-Old Fossil †Mengea Tertiaria (Insecta, Strepsiptera). Naturwissenschaften 2010, 97, 855-859. [CrossRef]

22. Arriaga-Varela, E.; Brunke, A.; Girón, J.C.; Szawaryn, K.; Bruthansová, J.; Fikáček, M. Micro-CT Reveals Hidden Morphology and Clarifies the Phylogenetic Position of Baltic Amber Water Scavenger Beetles (Coleoptera: Hydrophilidae). Hist. Biol. 2019, 33 , 1395-1411. [CrossRef]

23. Lak, M.; Néraudeau, D.; Nel, A.; Cloetens, P.; Perrichot, V.; Tafforeau, P. Phase Contrast X-ray Synchrotron Imaging: Opening Access to Fossil Inclusions in Opaque Amber. Microsc. Microanal. 2008, 14, 251-259. [CrossRef]

24. Metscher, B.D. MicroCT for Developmental Biology: A Versatile Tool for High-Contrast 3D Imaging at Histological Resolutions. Dev. Dyn. 2009, 238, 632-640. [CrossRef]

25. Metscher, B.D. MicroCT for Comparative Morphology: Simple Staining Methods Allow High-Contrast 3D Imaging of Diverse Non-Mineralized Animal Tissues. BMC Physiol. 2009, 9, 11. [CrossRef]

26. Martín-Vega, D.; Clark, B.; Ferrer, L.M.; López-Tamayo, S.; Panadero, R.; Cepeda-Palacios, R.; Colwell, D.D.; Hall, M.J.R. Major Differences in the Larval Anatomy of the Digestive and Excretory Systems of Three Oestridae Species Revealed by MICRO-CT. Med. Vet. Entomol. 2021, 35, 106-120. [CrossRef]

27. Poinapen, D.; Konopka, J.K.; Umoh, J.U.; Norley, C.J.D.; McNeil, J.N.; Holdsworth, D.W. Micro-CT Imaging of Live Insects Using Carbon Dioxide Gas-Induced Hypoxia as Anesthetic with Minimal Impact on Certain Subsequent Life History Traits. BMC Zool. 2017, 2, 9. [CrossRef]

28. Bray, D. Critical Point Drying of Biological Specimens for Scanning Electron Microscopy. In Supercritical Fluid Methods and Protocols; Humana Press: Totowa, NJ, USA, 2000; Volume 13, pp. 235-243; ISBN 978-1-59259-030-8.

29. Kitchen, M.J.; Buckley, G.A.; Gureyev, T.E.; Wallace, M.J.; Andres-Thio, N.; Uesugi, K.; Yagi, N.; Hooper, S.B. CT Dose Reduction Factors in the Thousands Using X-ray Phase Contrast. Sci. Rep. 2017, 7, 15953. [CrossRef] [PubMed]

30. Abrami, A.; Arfelli, F.; Barroso, R.C.; Bergamaschi, A.; Billè, F.; Bregant, P.; Brizzi, F.; Casarin, K.; Castelli, E.; Chenda, V.; et al. Medical Applications of Synchrotron Radiation at the SYRMEP Beamline of ELETTRA. Nucl. Instrum. Methods Phys. Res. Sect. A Accel. Spectrometers Detect. Assoc. Equip. 2005, 548, 221-227. [CrossRef]

31. Brun, F.; Massimi, L.; Fratini, M.; Dreossi, D.; Billé, F.; Accardo, A.; Pugliese, R.; Cedola, A. SYRMEP Tomo Project: A Graphical User Interface for Customizing CT Reconstruction Workflows. Adv. Struct. Chem. Imaging 2017, 3, 4. [CrossRef]

32. Keszthelyi, S.; Pónya, Z.; Csóka, Á.; Bázár, G.; Morschhauser, T.; Donkó, T. Non-Destructive Imaging and Spectroscopic Techniques to Investigate the Hidden-Lifestyle Arthropod Pests: A Review. J. Plant Dis. Prot. 2020, 127, 283-295. [CrossRef]

33. Ge, S.-Q.; Wipfler, B.; Pohl, H.; Hua, Y.; Ślipiński, A.; Yang, X.-K.; Beutel, R.G. The First Complete 3D Reconstruction of a Spanish Fly Primary Larva (Lytta Vesicatoria, Meloidae, Coleoptera). PLoS ONE 2012, 7, e52511. [CrossRef]

34. Racicot, R. Fossil secrets revealed: X-ray CT scanning and applications in Paleontology. Paleontol. Soc. Pap. 2016, 22, 21-38. [CrossRef]

35. Simonsen, T.J.; Kitching, I.J. Virtual Dissections through Micro-CT Scanning: A Method for Non-Destructive Genitalia 'Dissections' of Valuable Lepidoptera Material: Virtual Genitalia Dissection. Syst. Entomol. 2014, 39, 606-618. [CrossRef]

36. Hall, A.C.; Sherlock, E.; Sykes, D. Does Micro-CT Scanning Damage DNA in Museum Specimens? J. Nat. Sci. Collect. 2015, 2, 22-29.

37. Kapadia, R.D.; Stroup, G.B.; Badger, A.M.; Koller, B.; Levin, J.M.; Coatney, R.W.; Dodds, R.A.; Liang, X.; Lark, M.W.; Gowen, M. Applications of Micro-CT and MR Microscopy to Study Pre-Clinical Models of Osteoporosis and Osteoarthritis. Technol. Health Care 1998, 6, 361-372. [CrossRef] [PubMed]

38. Cnudde, V.; Boone, M.N. High-Resolution X-ray Computed Tomography in Geosciences: A Review of the Current Technology and Applications. Earth-Sci. Rev. 2013, 123, 1-17. [CrossRef]

39. Beutel, R.G.; Ge, S.; Hörnschemeyer, T. On the Head Morphology of Tetraphalerus, the Phylogeny of Archostemata and the Basal Branching Events in Coleoptera. Cladistics 2008, 24, 270-298. [CrossRef] 
40. Wipfler, B.; Courtney, G.W.; Craig, D.A.; Beutel, R.G. First $\mu$-CT-Based 3D Reconstruction of a Dipteran Larva-the Head Morphology of Protanyderus (Tanyderidae) and Its Phylogenetic Implications. J. Morphol. 2012, 273, 968-980. [CrossRef] [PubMed]

41. Spani, F.; Morigi, M.P.; Bettuzzi, M.; Scalici, M.; Gentile, G.; Carosi, M. The Ultimate Database to (Re)Set the Evolutionary History of Primate Genital Bones. Sci. Rep. 2021, 11, 11245. [CrossRef] [PubMed] 